\title{
An exploratory analysis of the relationship between paternal age at pregnancy and difficulties symptomatic of specific learning disorders among Japanese undergraduate students
}

\author{
Hiroki Ohmi ${ }^{1,2}$, Hiromi Muranaka², Haruko Hirano², Yachiyo Miyazaki², Misato Akanuma², \\ Daisuke Ogino ${ }^{3}$, and Martin Meadows ${ }^{3}$ \\ ${ }^{1}$ Department of Nutritional Sciences, Faculty of Health and Welfare Science, Nayoro City University, Japan \\ ${ }^{2}$ Health and Welfare Center, Nayoro City University, Japan \\ ${ }^{3}$ Department of Liberal Arts Education, Faculty of Health and Welfare Science, Nayoro City University, Japan
}

\begin{abstract}
Objective: Causes and risk factors of neurodevelopmental disorders originate in the prenatal and perinatal periods. Several studies have demonstrated a relationship between prenatal and perinatal medical records, including maternal and paternal age at pregnancy, and the neurodevelopmental disorders, especially attention deficit/hyperactivity disorder and autism spectrum disorder. However, previous studies showed an association between specific learning disorders and environmental toxins such as lead and tobacco smoke, but not parental age.

Patients and Methods: This study included 993 university freshmen, and their prenatal and perinatal medical data was collected from maternal and child handbooks. A mental health assessment questionnaire consisting of 24 items covering symptoms associated with neurodevelopmental disorders was administered, corresponding to aspects of attention deficit/hyperactivity disorder, autism spectrum disorder, and learning disorders. The relationship between prenatal and perinatal medical data and questionnaire results was statistically analyzed.

Results: The number of available records was 881 (88.7\%). Using Spearman's rank correlation coefficient analysis and trend analysis, a weak but statistically significant relationship was confirmed between paternal age at pregnancy and the score for learning disorder difficulties.

Conclusion: Error accumulation in meiosis during spermatogenesis may be one of the risk factors of learning disorders.
\end{abstract}

Key words: paternal age at pregnancy, difficulties symptomatic of specific learning disorders, error accumulation in meiosis during spermatogenesis, Japanese undergraduate students

(J Rural Med 2021; 16(1): 35-41)

\section{Introduction}

The number and percentage of university students showing symptoms associated with neurodevelopmental disorders have been increasing in the last 10 years according to

Received: April 7, 2020

Accepted: August 17, 2020

Correspondence: Hiroki Ohmi, Department of Nutritional Sciences, Faculty of Health and Welfare Science, Nayoro City University, W4-N8 Nayoro, Hokkaido 096-8641, Japan

E-mail: hiohmi@nayoro.ac.jp

This is an open-access article distributed under the terms of the Creative Commons Attribution Non-Commercial No Derivatives (by-nc-nd) License $<\mathrm{http}: / /$ creativecommons.org/ licenses/by-nc-nd/4.0/> studies conducted by the Japan Student Services Organization (JSSO) ${ }^{1)}$. In order to identify and support these students, mental health assessment questionnaires covering symptomatic difficulties associated with neurodevelopmental disorders have been administered to all freshmen since 2011. Neurodevelopmental disorders are classified into attention deficit/hyperactivity disorder (ADHD), autism spectrum disorder (ASD), specific learning disorders (LD), and others according to the diagnostic criteria of the Diagnostic and Statistical Manual of Mental Disorders, fifth edition ${ }^{2}$. The questionnaire consists of 24 items corresponding to the characteristic difficulties associated with ADHD, ASD, and LD.

Causes and risk factors of neurodevelopmental disorders may originate anytime during the developmental period, and they usually persist throughout a person's lifetime ${ }^{3-5}$. Most neurodevelopmental disorders begin before birth, but some 
develop after birth due to injury, infection, or other factors. Additionally, they could be caused by a complex mixture of factors including genetics, general parental health, maternal behaviors during pregnancy such as smoking and drinking, complications during childbirth, infections in the mother during pregnancy or in the baby very early in life, and exposure of the mother or child to high levels of environmental toxins.

In order to investigate the backgrounds and risk factors of neurodevelopmental disorders, we collected prenatal and perinatal medical data recorded in individual maternal and child handbooks of the university freshmen from 2013 to 2017. Maternal and child handbooks are given to all pregnant women in Japan, and a wide range of medical and personal data is recorded in them. We analyzed the relationship between prenatal and perinatal medical data recorded in these handbooks and the questionnaire results.

\section{Patients and Methods}

\section{Participants}

Participants were 993 freshmen (males: 150, females: 843; age 18-23 years) of the Nayoro City University from
2013 to 2017, belonging to the Faculty of Health and Welfare Science or the Department of Early Childhood Education.

\section{Data collection}

Students were asked to provide records from their maternal and child handbooks. The data included birth order; maternal and paternal age at pregnancy; maternal weight and height immediately before pregnancy; maternal smoking and drinking habits during pregnancy; presence (severity) or absence of pregnancy-induced hypertension (PIH) and gestational diabetes; presence or absence of neonatal asphyxia; gestational period and the child's weight, height, and head circumference at birth; and whether the child was breastfed, formula fed, or a combination of both. We analyzed only singleton births.

The perceived difficulties symptomatic of neurodevelopmental disorders of the students were obtained from a questionnaire consisting of 24 items corresponding to difficulties associated with ADHD, ASD, and LD. This was implemented as a mental health checklist upon university entry (Table 1). Items used to calculate the score for difficulties due to neurodevelopmental disorders were taken

Table 1 Questionnaire items for difficulties symptomatic of neurodevelopmental disorders

\begin{tabular}{|c|c|}
\hline Items & Scores \\
\hline $\begin{array}{l}\text { For ADHD } \\
\text { Are you easily distracted? } \\
\text { Do you lose things easily? } \\
\text { Do you often forget things? } \\
\text { Do you often act impulsively? } \\
\text { Do you have trouble keeping a regular lifestyle? } \\
\text { Do you have trouble keeping things tidy? } \\
\text { Do you have trouble meeting deadlines? } \\
\text { Do you often make careless mistakes at school or work? } \\
\text { Do you often hurt other people unintentionally? } \\
\text { Do you have trouble organizing things when you have a lot to do? }\end{array}$ & \\
\hline $\begin{array}{l}\text { For ASD } \\
\text { Do you have frequent mood swings? } \\
\text { Do you feel anxious when your normal daily routines are disrupted? } \\
\text { Do you often feel that others disapprove of your behavior? } \\
\text { Do you become upset when recalling past experiences? } \\
\text { Are you poor at inferring others' thoughts? } \\
\text { Are you confused about feeling of yourself as unusual? } \\
\text { Are there any specific sounds, odours or textures that bother you extremely? } \\
\text { Do you have trouble understanding tacit rules? }\end{array}$ & $\begin{array}{l}\text { 3: Yes } \\
\text { 2: Somewhat yes } \\
\text { 1: Somewhat no } \\
0: \text { No }\end{array}$ \\
\hline $\begin{array}{l}\text { For LD } \\
\text { Are there many typographical errors in your writing? (Are you poor at spelling? } \\
\text { Do you make a lot of spelling or typing mistakes?) } \\
\text { Is your handwriting messy and/or illegible? } \\
\text { Do you have trouble making out letters and words when reading? } \\
\text { Is your reading slow and labored? books fast? } \\
\text { Are you bad at math? } \\
\text { Do you have trouble taking notes during lectures? }\end{array}$ & \\
\hline
\end{tabular}


from questionnaires designed by Takahashi et al. ${ }^{6}$, and the National Institute of Special Needs Education and JSSO $^{7}$. The questionnaire consisted of 10, 8, and 6 question items concerning difficulties associated with ADHD, ASD, and LD, respectively. Responses were chosen using a Likert scale with the following four options: yes, somewhat yes, somewhat no, and no. Scores for each neurodevelopmental disorder were calculated separately.

\section{Statistical analysis}

Data were digitized and then analyzed with descriptive and non-parametric statistics in order to clarify the relationship between the prenatal and perinatal medical data and the questionnaire results. Statistical methods included rank testing (Mann-Whitney U-test and Kruskal-Wallis test), Spearman's rank correlation coefficient analysis, and trend analysis (Jonckheere-Terpstra test and Cochran-Armitage test). All $P$-values were based on a two-tailed test and values $<0.05$ were considered significant. Statistical analyses were performed using the IBM Statistical Package for the Social Sciences version 19.0.0 and EZR 1.40 ${ }^{8}$.

The protocol of this study was approved by the Ethics
Committee of Nayoro City University (approval number: 12-074).

\section{Results}

Among the 993 participants, nine females were excluded from analysis for twin birth. Valid responses from 881 students were obtained (recovery rate: $88.7 \%$ ). The characteristics of the participants analyzed in the prenatal and perinatal periods, and the student's age and scores for difficulties symptomatic of neurodevelopmental disorders are shown in Tables 2 and 3, respectively.

By the rank testing (Mann-Whitney U-test or KruskalWallis test), no significant relation was detected between difficulties symptomatic of neurodevelopmental disorders and the factors of sex, birth order, maternal smoking and drinking during pregnancy, presence (severity) or absence of PIH and gestational diabetes, presence or absence of neonatal asphyxia, and feeding in infancy.

The Spearman's rank correlation coefficients were examined to investigate the relationships between the scores for neurodevelopmental disorders and the maternal and pa-

Table 2 Characteristics of participants in prenatal and perinatal periods

\begin{tabular}{|c|c|c|c|c|c|c|c|}
\hline & & & $\begin{array}{c}\text { Available data } \\
\mathrm{n}\end{array}$ & Mean & SD & Min & Max \\
\hline \multirow[t]{13}{*}{ In prenatal period } & \multicolumn{2}{|l|}{ Maternal age at pregnancy (years) } & 881 & 28.7 & 4.3 & 17 & 42 \\
\hline & \multicolumn{2}{|c|}{ Paternal age at pregnancy (years) } & 877 & 30.9 & 5.1 & 17 & 47 \\
\hline & \multicolumn{2}{|c|}{ Maternal BMI at just prepregnancy $\left(\mathrm{kg} / \mathrm{m}^{2}\right)$} & 849 & 20.8 & 2.5 & 13 & 34 \\
\hline & \multirow[t]{2}{*}{ Maternal smoking during pregnancy } & No & 815 & & & & \\
\hline & & Yes & 63 & & & & \\
\hline & \multirow[t]{2}{*}{ Maternal drinking during pregnancy } & No & 838 & & & & \\
\hline & & Yes & 40 & & & & \\
\hline & \multirow[t]{3}{*}{ Pregnancy-induced hypertension } & No & 771 & & & & \\
\hline & & Yes, mild & 87 & & & & \\
\hline & & Yes, severe & 12 & & & & \\
\hline & \multirow[t]{3}{*}{ Gestational diabetes } & No & 865 & & & & \\
\hline & & Yes, mild & 7 & & & & \\
\hline & & Yes, severe & 0 & & & & \\
\hline \multirow[t]{11}{*}{ At birth } & \multirow[t]{3}{*}{ Birth order } & First & 448 & & & & \\
\hline & & Second or later & 432 & & & & \\
\hline & & Unknown & 1 & & & & \\
\hline & Gestational age (days) & & 863 & 276.0 & 9.3 & 216 & 300 \\
\hline & \multirow[t]{2}{*}{ Neonatal asphyxia } & No & 834 & & & & \\
\hline & & Yes & 18 & & & & \\
\hline & \multirow[t]{2}{*}{ Weight (kg) } & & Male: 127 & 3.089 & 0.356 & 2.208 & 3.992 \\
\hline & & & Female: 744 & 3.032 & 0.384 & 1.740 & 4.400 \\
\hline & \multirow[t]{2}{*}{ Height (cm) } & & Male: 124 & 49.2 & 1.8 & 45.0 & 53.7 \\
\hline & & & Female: 736 & 48.7 & 2.0 & 41.0 & 54.5 \\
\hline & Head circumference $(\mathrm{cm})$ & & 848 & 32.9 & 1.4 & 26.5 & 37.0 \\
\hline \multirow[t]{3}{*}{ In infancy } & \multirow[t]{3}{*}{ Feeding } & Breast & 325 & & & & \\
\hline & & Formula & 57 & & & & \\
\hline & & Mixture & 490 & & & & \\
\hline
\end{tabular}


Table 3 Student's age and the scores for difficulties symptomatic of neurodevelopmental disorders

\begin{tabular}{|c|c|c|c|c|c|c|c|c|}
\hline & & & $\begin{array}{c}\text { Available data } \\
\mathrm{n}\end{array}$ & Mean & $\mathrm{SD}$ & Median & Min & $\operatorname{Max}$ \\
\hline \multirow[t]{4}{*}{ Female and Male } & Age (years) & & 881 & 18.1 & 0.3 & 18 & 18 & 23 \\
\hline & \multirow[t]{3}{*}{ The scores for difficulties symptomatic of } & ADHD & 871 & & & 4 & 0 & 28 \\
\hline & & ASD & 868 & & & 2 & 0 & 19 \\
\hline & & LD & 870 & & & 1 & 0 & 17 \\
\hline \multirow[t]{4}{*}{ Female } & Age (years) & & 752 & 18 & 0.3 & 18 & 18 & 23 \\
\hline & \multirow[t]{3}{*}{ The scores for difficulties symptomatic of } & ADHD & 747 & & & 4 & 0 & 24 \\
\hline & & ASD & 744 & & & 2 & 0 & 19 \\
\hline & & LD & 746 & & & 1 & 0 & 17 \\
\hline \multirow[t]{4}{*}{ Male } & Age (years) & & 129 & 18.1 & 0.3 & 18 & 18 & 20 \\
\hline & \multirow[t]{3}{*}{ The scores for difficulties symptomatic of } & ADHD & 124 & & & 4 & 0 & 28 \\
\hline & & ASD & 124 & & & 2 & 0 & 18 \\
\hline & & LD & 124 & & & 2 & 0 & 14 \\
\hline
\end{tabular}

Table 4 Correlation between parental age and the scores for difficulties symptomatic of neurodevelopmental disorders

\begin{tabular}{llccc}
\hline & & \multicolumn{2}{c}{ The scores for difficulties symptomatic of } \\
\cline { 3 - 5 } & & ADHD & ASD & LD \\
\hline Maternal age & $\rho$ & 0.026 & 0.011 & 0.062 \\
& $P$ & $\mathrm{~ns}$ & $\mathrm{~ns}$ & $\mathrm{~ns}$ \\
& $\mathrm{n}$ & $871(\mathrm{~F}: 747, \mathrm{M}: 124)$ & $868(\mathrm{~F}: 744, \mathrm{M}: 124)$ & $870(\mathrm{~F}: 746, \mathrm{M}: 124)$ \\
\hline Paternal age & $\rho$ & 0.043 & 0.030 & 0.070 \\
& $P$ & $\mathrm{~ns}$ & $\mathrm{~ns}$ & 0.041 \\
& $\mathrm{n}$ & $867(\mathrm{~F}: 743, \mathrm{M}: 124)$ & $864(\mathrm{~F}: 740, \mathrm{M}: 124)$ & $866(\mathrm{~F}: 742, \mathrm{M}: 124)$
\end{tabular}

$\rho:$ Spearman's rank correlation coefficient. ns: not significant.

ternal age at pregnancy, maternal body mass index at pregnancy, gestational period, and child's weight, height, and head circumference at birth. Paternal age at pregnancy and the score for difficulties symptomatic of LD (LD difficulties) showed a positive correlation (Table 4), but there was no statistically significant difference with respect to sex. Moreover, other variables did not show a significant correlation with LD difficulties.

The trend analysis (Jonckheere-Terpstra test and Cochran-Armitage test) also indicated a significant positive trend between paternal age at pregnancy and LD difficulties (Table 5 and Figure 1), but there was no statistically significant difference with respect to sex.

The Spearman's rank correlation coefficient analysis revealed mutually strong positive correlations among the scores for difficulties symptomatic of neurodevelopmental disorders (Table 6).

\section{Discussion}

\section{Main findings}

Several studies have suggested that the backgrounds and risk factors of neurodevelopmental disorders are related to prenatal and perinatal environments, such as maternal smoking and drinking during pregnancy, PIH, and neonatal asphyxia $^{3-5)}$. However, in this study, no significant relation was demonstrated statistically, except between paternal age at pregnancy and LD difficulties. This could be attributed to the small sample size of this study. Previous studies suggesting a relationship between prenatal and perinatal environments and the neurodevelopmental disorders were either conducted with larger sample sizes or they were case-control studies $^{9,10)}$. Maternal smoking during pregnancy, drinking during pregnancy, PIH (including mild cases), gestational diabetes, and neonatal asphyxia accounted for $7.2 \%, 4.6 \%$, $10.9 \%, 0.8 \%$, and $2.1 \%$ of the participants, respectively. Analysis with a larger sample size might be necessary.

On the other hand, a weak but statistically significant as- 
sociation was found between paternal age at pregnancy and LD difficulties. Data pertaining to paternal age at pregnancy was available in $99.5 \%$ of the participants, which could provide just enough statistical power to detect an association. Several studies have demonstrated the relationships between paternal age at pregnancy and the psychological/behavioral disorders including neurodevelopmental disorders ${ }^{9-14)}$. With respect to neurodevelopmental disorders, an association between paternal age at pregnancy and the offspring's ADHD, ASD, and intellectual disability has been demonstrated in previous publications ${ }^{9-14)}$. This was supposed to be due to error accumulation in meiosis upon spermatogenesis ${ }^{11,13,15)}$. However, an association between paternal age at pregnancy and offspring's LD has not been detected in previous studies. There have been several studies indicating a relationship between environmental toxins, such as lead and tobacco smoke, and $\mathrm{LD}^{3)}$. Recent trends of increase in the percentage of elderly fathers in Japan may be concerning ${ }^{19)}$.

Individual scores for difficulties symptomatic of ADHD, ASD, and LD were closely related. Previous studies by us and other authors have shown similar results ${ }^{3,16)}$. This might indicate that backgrounds and risk factors for these three neurodevelopmental disorders are similar or interrelated. In this study, however, no significant association was demonstrated between paternal age at pregnancy and the scores for difficulties symptomatic of ADHD and ASD. The influence of paternal age on neuronal development relating to neurodevelopmental disorders might differ slightly from each other").

Table 5 Trend analysis between parental age and learning disorder difficulties

\begin{tabular}{|c|c|c|}
\hline & \multicolumn{2}{|c|}{$P$} \\
\hline & Jonckheere-Terpstra test & Cochran-Armitage test \\
\hline Maternal age & ns & ns \\
\hline Paternal age & 0.049 & 0.013 \\
\hline
\end{tabular}

In Cochran-Armitage test, parental age was stratified for three age groups, i.e. below 24 years, 25-34 years, and over 35 years.

\section{Limitations}

This study was conducted in a small university in Hokkaido with a small sample size. The university is located in Hokkaido, but not all of the students are from there. About $60 \%$ are from Hokkaido, while the remaining $40 \%$ are from

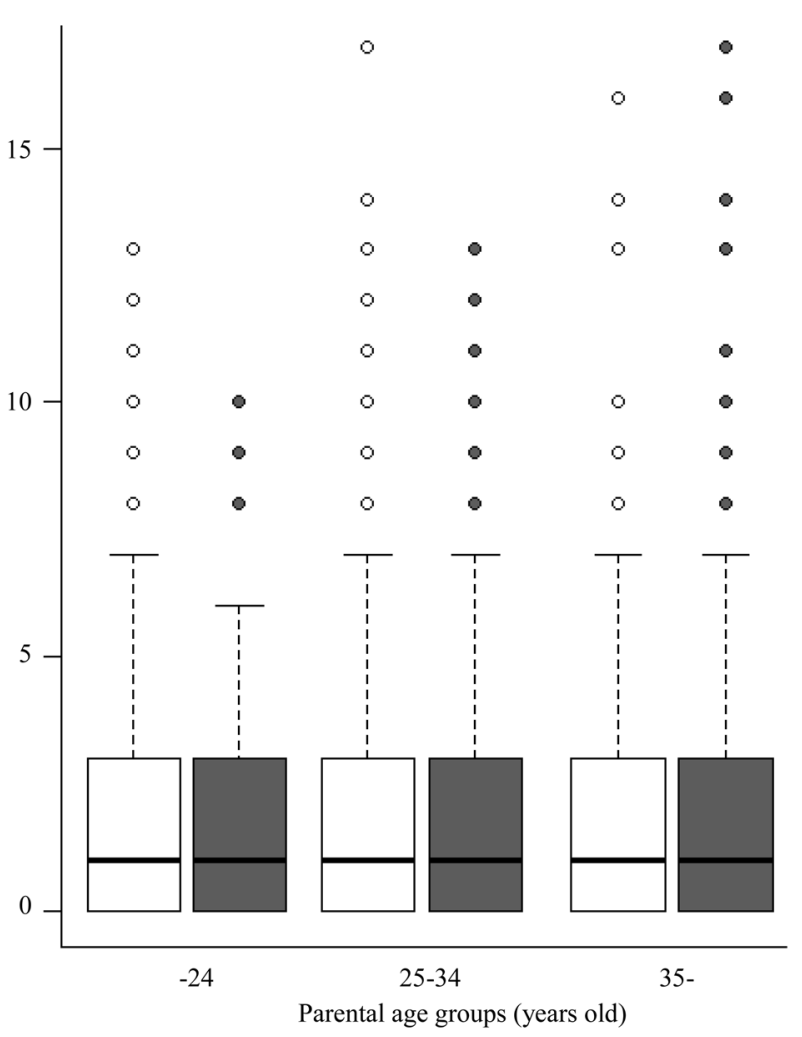

Figure 1 Box and whisker plot of the learning disorder (LD) difficulties according to parental age group at pregnancy. Blank boxes and circles indicate distributions according to maternal age, and hatched boxes and circles indicate distributions according to paternal age, respectively.

Bottom and tops of boxes indicate 25 and $75 \%$ of the scores, respectively, and the upper ends of whiskers indicate $90 \%$ of scores.

Table 6 Correlation among the scores for difficulties symptomatic of neurodevelopmental disorders

\begin{tabular}{|c|c|c|c|c|c|c|c|}
\hline & & \multicolumn{6}{|c|}{ The scores for difficulties symptomatic of } \\
\hline & & \multicolumn{2}{|c|}{ Female and Male } & \multicolumn{2}{|c|}{ Female } & \multicolumn{2}{|c|}{ Male } \\
\hline & & ASD & LD & ASD & LD & ASD & LD \\
\hline \multirow[t]{3}{*}{ The scores for difficulties symptomatic of ADHD } & $\rho$ & 0.633 & 0.505 & 0.624 & 0.502 & 0.696 & 0.521 \\
\hline & $P$ & $<0.001$ & $<0.001$ & $<0.001$ & $<0.001$ & $<0.001$ & $<0.001$ \\
\hline & $\mathrm{n}$ & 867 & 869 & 743 & 745 & 124 & 124 \\
\hline \multirow[t]{3}{*}{ The scores for difficulties symptomatic of ASD } & $\rho$ & & 0.466 & & 0.472 & & 0.433 \\
\hline & $P$ & & $<0.001$ & & $<0.001$ & & $<0.001$ \\
\hline & $\mathrm{n}$ & & 868 & & 744 & & 124 \\
\hline
\end{tabular}

$\rho:$ Spearman's rank correlation coefficient. 
Honshu, Shikoku, and Kyushu. There were no reports of differences in the prevalence of $\mathrm{LD}$ among the different regions of Japan.

The association between paternal age at pregnancy and the offspring's neurodevelopmental disorders has been shown in previous publications ${ }^{9-14}$. This was attributed to the error accumulation in meiosis upon spermatogenesis. The "Y" chromosome in males and one of the two " $\mathrm{X}$ " chromosomes in females are of paternal origin. If the " $X$ " and "Y" chromosomes have the same probability of error, a high probability of a problem with the " $\mathrm{X}$ " chromosome is suggested, which has more exons. However, the prevalence of LD was reportedly 2-3 times higher in males ${ }^{2}$, but we could not find any reports that explained this.

The questionnaire consisted of only 24 items, and they were not based on tools such as the Diagnostisch Interview Voor ADHD bij volwassenen or the Autism-spectrum quotient (AQ), both of which are widely acclaimed ${ }^{17,18)}$. Because the aim of our mental health check-ups was not to provide a diagnosis, but rather screen students who may have difficulties symptomatic of neurodevelopmental disorders, the number of questionnaire items was minimized to obtain a high response rate. Therefore, cut-off scores for difficulties symptomatic of neurodevelopmental disorders were not set. LDs are comprised of the following sub-categories: reading disorder (dyslexia), writing disorder (dysgraphia), math dis- ability (discalculia), and others ${ }^{2}$. We did not analyze these separately because of the small sample size. Because we collected prenatal and perinatal medical data recorded in individual maternal and child handbooks, we could not analyze the information that was not recorded in them.

In Tables 4 and 5, the combined analysis of both sexes showed a significant difference. However, there was no significant difference when analyzed by sex probably because it was on the border statistically. To elucidate definitive associations, future studies need to be conducted with a larger sample with more precise criteria, and extensive data collection and analysis are required.

\section{Conclusion}

We analyzed the relationship between prenatal and perinatal medical data and scores for difficulties symptomatic of neurodevelopmental disorders in Japanese university freshmen. A weak but statistically significant association was confirmed between paternal age at pregnancy and LD difficulties. Error accumulation in meiosis upon spermatogenesis may be one of the risk factors of LD.

Conflicts of interest: This study was not supported by any funding. None of the authors had a conflict of interest to declare.

\section{References}

1. Japan Student Services Organization Fact-finding investigation on the study support of students of universities, junior colleges and colleges of technology with Neurodevelopmental Disorder. https://www.jasso.go.jp/gakusei/tokubetsu_shien/chosa_kenkyu/chosa/_icsFiles/afieldfile/2019/03/19/analysis2016. pdf (in Japanese). (Accessed: February 2020).

2. American psychiatry association. Neurodevelopmental disorders. In: Diagnostic and statistical manual of mental disorders: DSM-5. Amer Psychiatric Pub Inc, $2013 ; 31-86$.

3. United States Environmental Protection Agency Health: Neurodevelopmental disorders. https://www.epa.gov/sites/production/files/2019-07/documents/ ace3-neurodevelopmental-updates_0.pdf. (Accessed: February 2020).

4. Mill J, Petronis A. Pre- and peri-natal environmental risks for attention-deficit hyperactivity disorder (ADHD): the potential role of epigenetic processes in mediating susceptibility. J Child Psychol Psychiatry 2008; 49: 1020-1030. [Medline] [CrossRef]

5. Sugie Y, Sugie H. [Perinatal and neonatal risk factors for autism spectrum disorders]. Seishin Shinkeigaku Zasshi 2009; 111: 1397-1403 (in Japanese). [Medline]

6. Takahashi T, Iwabuchi M, Suda N, et al. Implementation Manual of questionnaires on difficulties with Neurodevelopmental Disorders. Sankei-sha, Nagoya, 2012 (in Japanese).

7. National Institute of Special Needs Education, Japan Student Services Organization A study on support of students in higher education institutions with neurodevelopmental Disorders. http://www.nise.go.jp/kenshuka/josa/kankobutsu/pub_g/g-8.pdf (in Japanese). (Accessed: February 2020).

8. Kanda Y. Investigation of the freely available easy-to-use software 'EZR' for medical statistics. Bone Marrow Transplant 2013; 48: 452-458. [Medline] [CrossRef]

9. D'Onofrio BM, Rickert ME, Frans E, et al. Paternal age at childbearing and offspring psychiatric and academic morbidity. JAMA Psychiatry 2014; 71: 432-438. [Medline] [CrossRef]

10. Tsuchiya KJ, Matsumoto K, Miyachi T, et al. Paternal age at birth and high-functioning autistic-spectrum disorder in offspring. Br J Psychiatry 2008 ; 193 : 316-321. [Medline] [CrossRef]

11. Idring S, Magnusson C, Lundberg M, et al. Parental age and the risk of autism spectrum disorders: findings from a Swedish population-based cohort. Int $\mathrm{J}$ Epidemiol 2014; 43: 107-115. [Medline] [CrossRef]

12. Croen LA, Najjar DV, Fireman B, et al. Maternal and paternal age and risk of autism spectrum disorders. Arch Pediatr Adolesc Med 2007; 161: 334-340. [Medline] [CrossRef]

13. Saha S, Barnett AG, Foldi C, et al. Advanced paternal age is associated with impaired neurocognitive outcomes during infancy and childhood. PLoS Med 2009; 6: e40. [Medline] [CrossRef] 
14. Janecka M, Hansen SN, Modabbernia A, et al. Parental age and differential estimates of risk for neuropsychiatric disorders: findings from the Danish Birth cohort. J Am Acad Child Adolesc Psychiatry 2019; 58: 618-627. [Medline] [CrossRef]

15. Malaspina D, Gilman C, Kranz TM. Paternal age and mental health of offspring. Fertil Steril 2015; 103: 1392-1396. [Medline] [CrossRef]

16. Ohmi H, Muranaka H, Hirano H, et al. Relationships among mental health surveys: Patient Health Questionnaire-9 and diffi culties related to developmental disorders (attention deficit hyperactivity disorder, autistic spectrum disorder and learning disabiliy). Camputh Health 2016; 53: 115-120 (in Japanese, Abstract in English).

17. Kooij JJS, Francken MH. Diagnostic Interview voor ADHD bij volwassenen (DIVA) https://www.divacenter.eu/Content/VertalingPDFs/DIVA_2_Japanese_form.pdf (in Japanese, translated to Japanese by Nakamura K). (Accessed: February 2020).

18. Wakabayashi A, Tojo Y, Baron-Cohen S, et al. [The Autism-Spectrum Quotient (AQ) Japanese version: evidence from high-functioning clinical group and normal adults]. Shinrigaku Kenkyu 2004; 75: 78-84 (in Japanese). [Medline] [CrossRef]

19. Health, Labour and Welfare Statistics Association. Vital statistics. In: Journal of Heath and Welfare Statistics. 66: 2019/2020 Health, Labour and Welfare Statistics Association, Tokyo, 2019, 56-80. 